
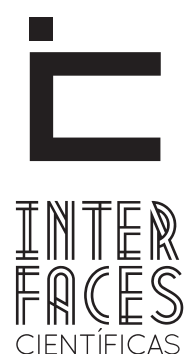

EDUCAÇÃO

ISSN IMPRESSO 2316-333X

ISSN ELETRÔNICO 2316-3828

DOI 10.17564/2316-3828.2015v4n1p57-66

\title{
A EDUCAÇÃO ESCOLAR NO INÍCIO DA COLONIZAÇÃO DO NORTE DO PARANÁ: A ESCOLA BRATISLAVA, DE CAMBÉ [1936-1948]
}

\section{RESUMO}

0 tema deste texto é a educação escolar no início da colonização do Norte do Paraná. Para tal, é apresentada a história de uma escola rural na região de Cambé, a Escola Bratislava, que foi fundada no ano de 1936. A investigação está situada no campo da História e da Historiografia das Instituições Escolares. O objetivo do trabalho é reconstruir a história e a memória da Escola Bratislava, por meio do levantamento e da análise de fontes e informações, no intuito de contribuir não só com a preservação da memória da instituição, mas também com o estudo da história das instituições escolares da região, para isso, foram utilizadas fontes documentais e iconográficas, analisadas a partir do método que relaciona o singular com o geral, fazendo uma análise de contexto. A reconstituição da história da Escola Bratislava permite afirmar que a educação escolar oferecida pela instituição aconteceu em meio há um processo de resistência, por parte dos mora- dores, às políticas nacionalistas da Era Vargas (19301945). Os moradores da região viam na instituição a oportunidade de preservar a identidade étnica do grupo. Entretanto, as políticas de nacionalização se fizeram presentes na colônia, o que culminou com a municipalização da instituição no ano de 1944, a qual, ao ser assumida pelo poder público, tornou-se uma porta-voz dos ideais patrióticos e do projeto nacionalista do Governo Vargas (1930-1945). Assim, a maneira como a escola estava organizada fez dela uma instituição de referência, o que permitiu a sua permanência até o presente momento numa região em crescente expansão urbana.

\section{PALAVRAS-CHAVE}

Educação. História da Educação. Instituições Escolares. Paraná. Escola Bratislava. 


\section{ABSTRACT}

The topic of the text is school education in the beginning of the colonization of Northern Paraná. To that end, the history of a rural school in the region of Cambé, the Bratislava School, founded in 1936, is presented. The scope of this investigation includes the field of History and Historiography of Educational Institutions. The objective of this work is to reconstruct the history and the memory of the Bratislava School through the survey and analysis of sources and information contributing not only to the memory and preservation of the institution but also to the study of the schools in the region. To do so, documental and iconographic sources, analyzed by a method that relates the singular to the general, were used to make a context analysis. The reconstitution of the history of the Bratislava School shows that the education offered by the institution took place under a process of

\section{RESUMEN}

El tema de este texto es la educación escolar al principio de la colonización del norte del Estado de Paraná, Brasil. Para eso, es presentada un recorrido histórico de una escuela rural de la región de Cambé, la Escuela Bratislavia, que fue fundada en el año de 1936. La investigación está ubicada en el campo de la historia e de la historiografía de las Instituciones Escolares. El propósito de este trabajo es reconstruir la historia y la memoria de la Escuela Bratislava, por medio levantamiento y del análisis de fuentes e informaciones, con el objetivo de contribuir no solo con la preservación de la memoria de la institución, sino con el estudio de la historia de las instituciones escolares de la región, para eso, fueron utilizadas fuentes documentales e iconográficas, analizadas a partir de un método que relaciona el singular con lo general, volviendo un análisis de contextos. La reconstitución de la historia de la Escuela Bratislava permite afirmar que la educación escolar ofrecida por la institución ocurrió en resistance to the nationalist policies of the Vargas Era (1930-1945) by the inhabitants. Region dwellers saw in the institution an opportunity to preserve the ethnic identity of the group. However, nationalization policies were present in the colony, which culminated with the municipalization of the institution in 1944. By being administered by the public sector, it became the mouthpiece of the patriotic ideals and the nationalistic project that prevailed in the society at that time. Thus, the way the school was organized turned it into a reference, consolidating its presence, until now, in a region with great urban expansion.

\section{KEYWORDS}

Education. History of Education. Educational Institutions. Paraná. Bratislava School. medio a un proceso de resistencia, por parte de los vivientes, a las políticas nacionales de la Era Vargas (1930-1945). Los vivientes de la región veían en la institución la oportunidad de preservar la identidad étnica del grupo. No obstante, las políticas de nacionalización se volvieron presente en la colonia, lo que culminó con la municipalización de la institución en el año de 1944, la cual, al asumirse por el poder público, que hizo un porta-voz de los ideales patrióticos y del proyecto nacionalista que pairaba en la sociedad. Así, el modo como la escuela estaba organizada hizo de ella una de la instituciones de referencia, lo que permitió su permanencia hasta el presente momento en una región en creciente expansión urbana.

\section{PALABRAS CLAVES}

Educación. Historia de la Educación. Instituciones Escolares. Paraná. Escuela Bratislava 


\section{INTRODUCÃO}

Este estudo está situado no campo da História das Instituições Escolares e tem como objeto de análise a Escola Bratislava de Cambé, instalada no ano de 1936 na região rural de Cambé, no estado do Paraná. A instituição foi fundada com o objetivo de resguardar a formação étnica e cultural do grupo, o qual era composto por imigrantes naturais de Danzig, que chegaram à região no ano de 1932 por meio de uma parceria firmada entre a Companhia de Terras Norte do Paraná (CTNP) e o Senado de Danzig. ${ }^{2}$ Esses imigrantes foram instalados na região rural da atual Cambé, no Norte do Paraná, quando a cidade estava em processo de reocupação, também conhecido pela história "oficial" como colonização. 0 termo colonização é baseado no mito do vazio demográfico da região. Entretanto, a região era habitada por indígenas, caboclos e posseiros, os quais foram expulsos para que acontecesse o processo de venda de lotes a estrangeiros e migrantes para a formação de núcleos urbanos (TOMAZI, 1997).

Ciente da problemática que envolve o uso do termo colonização e sem ter a intenção de fazer apologia ao mito do "vazio demográfico", este trabalho faz a análise da história da Escola Bratislava a partir do contexto histórico em que ela foi criada. Para tanto, foi realizado um estudo histórico-documental pautado na metodologia que relaciona o particular à totalidade, em uma relação dialética.

\section{BREVE CONTEXTO HISTÓRICO: DO BRASIL REPUBLICANO À ERA VARGAS [1889-1945]}

A sociedade brasileira passou por muitas mudanças durante o período conhecido como Primeira República (1889-1930). Essas mudanças ocorreram tanto

2. Danzig era uma cidade portuária situada no "corredor polonês", em meio à disputa por território entre Alemanha e Polônia, ora pertenceu à Alemanha, ora à Polônia. Em 1919, com o Tratado de Versalhes, Danzig se tornou uma cidade livre. Após a Segunda Guerra Mundial, passou a fazer parte da Polônia e recebeu o nome de Gdansk (CORTEZ, 2012). no campo político e econômico quanto no educacional. 0 fim do sistema escravista, também, marcou o início do século XX. Nesse período, houve a ascensão de uma burguesia urbana, o que contribuiu para o desenvolvimento industrial do país. Conflitos militares nacionais e internacionais, como a Primeira Guerra Mundial (1914-1918), contribuíram para a reorganização política e econômica do país durante a década de 1920 (RENK, 2012).

A imigração de estrangeiros europeus para o Brasil foi motivada pela industrialização desses países, o que gerou desemprego e miséria para os camponeses. No Brasil, na iminência da abolição da escravatura, os produtores de café de São Paulo conseguiram do governo estadual a subvenção para trazer ao país a mão de obra europeia, barata, em substituição à mão de obra nacional (RENK, 2012).

No Brasil, não havia falta de mão de obra, entretanto, a elite brasileira tinha a ideia de que os trabalhadores nacionais eram preguiçosos e "caipiras", enquanto os trabalhadores europeus eram vistos como disciplinados para o trabalho livre e portadores dos elementos de civilização, e, dessa maneira, poderiam cumprir o propósito do branqueamento da raça e da civilização do povo brasileiro (HALL, 1989).

Cerca de 3,8 milhões de estrangeiros entraram no Brasil entre o período do final do Império até o início da Primeira República. Esses imigrantes vieram para atuar, prioritariamente, nas lavouras de café. No entanto, a Primeira Guerra Mundial foi um fator que dificultou o fluxo de imigrantes para o país, o qual só voltou a receber os estrangeiros após o término do conflito (FAUSTO, 1999).

As mudanças que aconteceram na sociedade brasileira no período republicano, também, influenciaram o campo educacional, pois havia um discurso de que por meio da educação laica e gratuita se formaria o novo 
modelo de homem. Para isso, os republicanos pensaram na educação como aquela que deveria transformar os antigos súditos em cidadãos e exercer a função de nacionalizar os imigrantes, dando a eles a noção de pertencer à nação brasileira e, ainda, instaurando a democracia por meio da formação dos eleitores.

A Primeira República findou em meio à crise social, econômica e política partidária que corroborou para que Getúlio Vargas, por meio de um golpe de Estado, assumisse a presidência da República no ano de 1930, dando origem à “Era Vargas” (1930-1945), marcada por um "governo centralizador, unitário e antiparlamentar” (FAUSTO, 1999, p. 20).

A Era Vargas foi dividida, historicamente, em dois momentos importantes. O primeiro foi de 1930 até 1937, conhecido como governo provisório, já o outro momento, foi de 1937 até 1945 . Esse período ficou conhecido como Estado Novo.

Getúlio Vargas assumiu a Presidência da República em um período em que o Brasil refletia os efeitos da crise mundial. Problemas como a falta de estradas para o escoamento da produção e a necessidade de reforma tributária marcaram o final da Primeira República, período que corresponde ao início do processo de declínio do sistema agrícola, bem como das oligarquias agrárias, e da ascensão da burguesia urbana brasileira.

Para diminuir os efeitos da crise cafeeira, Vargas realizou uma série de medidas para a valorização dos produtos brasileiros. Essas medidas foram vistas como nacionalistas e atingiram os setores produtivos no Brasil. Vargas decretou a Lei conhecida como “Dois terços", na qual dois terços dos funcionários das empresas deveriam ser brasileiros natos. Também foi proibida a importação de vários produtos, inclusive máquinas, com o objetivo de valorizar a produção brasileira (FAUSTO, 1999).

Esse movimento nacionalista atingiu vários setores, entre os quais a educação na década de 1930, que foi acometida de uma série de leis e decretos que versavam sobre o ensino nas escolas brasileiras. Essa década foi marcada, também, pelo Manifesto dos Pioneiros da Educação, que foi um documento elaborado por um grupo de intelectuais e políticos brasileiros que criticavam o modelo de educação tradicional em vigor e sugeriam uma educação gratuita, pública e laica.

Getúlio Vargas, quando esteve no poder, utilizou das políticas nacionalistas para construir a noção de patriotismo e de pertence, principalmente nos estrangeiros que habitavam as terras brasileiras. Para tal, utilizou a educação escolar em prol do projeto de formação do cidadão nacional. Tais políticas determinaram o rumo educacional do país, principalmente nas regiões em processo de colonização, como o Norte do Paraná.

\section{O PROCESSO DE REOCUPAÇÃO DO NORTE PARANAENSE}

A ocupação da região Norte do Paraná aconteceu pautada no discurso das terras desocupadas e do vazio demográfico. A imagem das terras vazias esteve muito presente nos documentos oficiais e nos livros didáticos que narravam a história da região. Esse discurso foi produzido pela classe dominante, a qual tinha o interesse em expandir o sistema capitalista. Para isso, era necessário "vender" a ideia de que as terras do Norte do Paraná eram desocupadas e precisavam de desbravadores para colonizar a região (NOELLI; MOTA, 1999).

As propagandas enaltecendo a alta fertilidade das terras roxas do Norte do Paraná atraíram muitos imigrantes europeus, entre eles estavam alemães, portugueses, japoneses, italianos, poloneses, eslavos, ucranianos, tchecos e russos, além de muitos paulistas e mineiros (STECA; FLORES, 2002).

A colonização da região Norte e Norte Novo aconteceu por meio da parceria entre o Estado do Paraná e empresas privadas, pois havia muitos interesses eco- 
nômicos e políticos na reocupação da região. Dessa forma, o processo de imigração no Paraná aconteceu para povoar o território e diversificar as atividades econômicas; e, em segundo, para formar a classe média (NOELLI; MOTA, 1999).

Para que as políticas do governo de colonização das terras paranaenses tivessem sucesso e a região Norte do Paraná pudesse ser colonizada, muitos moradores foram expulsos da região com base na Lei de Terras, aprovada em 18 de setembro de 1850, que versava sobre as terras "devolutas" do Império. A lei determinava que era necessário que se comprovasse a propriedade das terras por meio de documentos, e na ausência deles as terras eram reintegradas ao Estado, que firmou parceria com algumas empresas privadas com a responsabilidade de colonizar a região. Entre essas empresas, estava a Companhia de Terras Norte do Paraná.

A partir de 1920, a Companhia de Terras Norte do Paraná, responsável pela colonização da região Norte Novo, iniciou o processo de colonização mediante a venda de lotes urbanos e rurais.

\begin{abstract}
Algumas características da colonização, como a organização em pequenas e médias propriedades (principalmente no norte novo e novíssimo) cultivadas a partir da produção familiar, a facilitação nas formas de pagamento da terra e o planejamento de uma rede de cidades que atendessem às necessidades da população rural, foram criadas a partir da ação das companhias colonizadoras. É importante destacar que tais características, aliadas ao solo de terra roxa (nitossolo), muito fértil, propiciando grande produtividade aos cafeeiros, foram fatores decisivos para atrair famílias de outras regiões do país, principalmente mineiros e paulistas, ao norte do Paraná, a fim de cultivarem o café. (CHIES; YOKOO, 2012, p. 28).
\end{abstract}

O cultivo do café foi um dos fatores que contribuíram para o desenvolvimento da região, pois os migrantes e imigrantes que compraram lotes na região se dedicaram ao cultivo do café. Nesse contexto, Londrina foi fundada em 22 de agosto de 1929, dando início ao projeto da CTNP de construir quatro grandes cidades na região Norte, sendo elas: Londrina, Marin- gá, Cianorte e Umuarama. Essas cidades foram planejadas com uma distância de cerca de 100 quilômetros. Entre elas, foram construídas cidades menores, como é o caso de Cambé, que fica ao lado de Londrina.

Tanto o governo quanto as empresas privadas investiram em propagandas que divulgavam as terras férteis do Norte Paranaense. Além das propagandas, a empresa responsável pela colonização, também, firmou acordos internacionais com regiões da Europa para trazer imigrantes para a região. No início da década de 1930, foi firmado um acordo entre a CTNP e o Senado de Danzig, que previa a emigração para o Norte do Paraná. Esses imigrantes se estabeleceram na região de Londrina e fundaram um patrimônio nomeado Nova Dantzig. 0 nome dado à região foi escolhido pela Companhia de Terras Norte do Paraná em homenagem aos imigrantes que vieram de Danzig. 0 patrimônio foi dividido em zona rural, a qual era chamada de Neu Danzig, e centro urbano, conhecido como Nova Dantzig (STECA; FLORES, 2002).

A presença de estrangeiros no Paraná contribuiu com o aumento populacional que originou o surgimento de várias regiões e também com o desenvolvimento educacional, a partir da criação de escolas nos núcleos por eles habitados.

0 aumento populacional e o desenvolvimento da região foram marcados por políticas de ocupação territorial. Assim como no restante do país, o Paraná também foi influenciado por ideais de modernização e desenvolvimento. Nesse aspecto, a educação foi:

\footnotetext{
[...] concebida como elemento indispensável ao progresso social, tornando-se tema de debates, foi destacada como algo fundamental para a formação do cidadão, no processo de assimilação cultural por imigrantes e na preparação para o trabalho. 0 ideário da necessidade de educar as classes populares e dispor maior oferta de educação a toda a população em condições de recebê-la fortaleceu-se ao lado do entendimento de que problemas sociais poderiam ser resolvidos, em parte, pela educação. (MELO; MACHADO, 2010, p. 248)
} 
No Paraná, a presença de imigrantes europeus contribuiu com a abertura de escolas étnicas, que deram início ao processo educacional em muitas regiões do Estado, principalmente nas regiões de recente colonização. No caso de Cambé, foram duas as escolas, a saber, a Escola Alemã e a Escola Bratislava.

\section{EDUCAÇ̃̃O ESCOLAR EM CAMBÉ: DA PRIMEIRA ESCOLA PRIVADA À ESCOLA BRATISLAVA}

A educação escolar em Cambé teve início no ano de 1934, quando ainda era denominada Nova Dantzig, e foi por meio de uma iniciativa particular. Com o objetivo de atender às crianças que moravam na região central de Nova Dantzig, a primeira escola privada de Cambé foi fundada no dia $1^{\circ}$ de agosto de 1934 pela professora Izaura Ferreira Neves, filha de um funcionário da CTNP. O pai da professora Izaura contribuiu para a abertura da escola, pois a Companhia de Terras ajudava as pessoas que se prontificavam a abrir empreendimentos que contribuíssem com o desenvolvimento das regiões colonizadas (NEVES,1985).

A escola funcionou, durante alguns meses, entre as avenidas Inglaterra e Brasil. Contudo, no dia 28 de fevereiro de 1935, Izaura Ferreira Neves foi nomeada professora municipal pelo então prefeito de Londrina Joaquim Vicente de Castro, e, ao ser nomeada, a professora passou a receber a quantia de 170 mil réis mensais. Assim, a escola foi então municipalizada, e a nomeação da professora foi considerada o marco do ensino público em Cambé (CAMBÉ, 1992).

A história da educação escolar em Cambé é marcada, também, pela abertura de uma escola étnica no ano de 1935, a Escola Alemã. A escola foi fundada por um grupo de imigrantes oriundos de Danzig, mas que falavam o idioma alemão. 0 grupo, composto por 63 pessoas, foi responsável por organizar uma associação escolar com o compromisso de construir e manter a Escola Alemã funcionando.
As associações culturais e escolares e as congregações religiosas foram muito importantes na construção e manutenção das escolas étnicas, pagamento dos professores, aquisição de material didático e organização pedagógica, reforçando a importância do associativismo. (RENK, 2012, p. 1048).

A Escola Alemã era um “tipo" de sociedade-escola, que era um modelo de escola comunitária construída e mantida pela comunidade, e que era utilizada também como espaço da sociedade cultural.

\begin{abstract}
As associações criadas no país, mais a comunidade, a igreja e as escolas, tinham por objetivo garantir a relação com a Alemanha, relação essa que deixaram para traz. Nestas instituições, os objetivos curriculares e extracurriculares tinham que manter as mesmas atividades organizadas nas escolas, de onde partiram para que assegurassem a manutenção das relações culturais com a pátria de origem, a Alemanha. (EIDAM; NASCIMENTO, 2011, p. 2).
\end{abstract}

Apesar de muitas escolas étnicas terem sido fechadas no Paraná, no ano de 1938, com as políticas governamentais de nacionalização, a Escola Alemã esteve em atividade até o ano de 1942, quando foi confiscada pelo Governo Brasileiro no período em que o Brasil declarou guerra à Alemanha e seus aliados. Depois de confiscada, ela foi transformada em extensão do primeiro grupo escolar de Cambé, o Grupo Escolar “Olavo Bilac”, fundado no ano de 1940 (CORTEZ, 2012).

No Brasil, na década de 1930, muitas escolas foram instituídas, étnicas ou não, principalmente em regiões rurais, habitadas, em sua maioria, por estrangeiros europeus. Nesse período, a educação rural passou a ser vista como o meio mais eficaz de fixação do homem no campo. Para isso, o governo estadual incentivou a reocupação das regiões paranaenses tidas como "espaços vazios" e passou a desenvolver uma política de constituição da educação formal no meio rural, com o objetivo de fixar os colonos nessas áreas, garantindo assim o sustento agrícola do país. 


\subsection{A PRIMEIRA ESCOLA RURAL DE CAMBÉ: ESCOLA BRATISLAVA}

No ano de 1936, foi inaugurada, na Colônia Bratislava, em Cambé, a Escola Bratislava, considerada a primeira escola rural, também de origem étnica, que iniciou as atividades por meio da iniciativa de um grupo de estrangeiros vindos de Danzig. 0 grupo era composto por 27 pessoas, entre adultos e crianças. 0 grupo chegou a Londrina em dezembro de $1931 \mathrm{com}$ a missão de fundar a colônia Neu Danzig, na zona rural de Cambé, localizada entre a vila urbana de Nova Dantzig (Cambé) e os arredores de Londrina.

Assim como de costume, as comunidades estrangeiras ao se deslocarem para regiões de recente colonização, instalavam escolas, para tal, organizavam-se em associações. No caso da Colônia Bratislava, para a construção e a manutenção da escola, foi composta a "Sociedade Escolar Brasileira da Colônia Bratislava", designada sociedade civil com fins educacionais.

\begin{abstract}
As escolas étnicas tinham uma existência fora do aparelho estatal, mas a característica comum era a de ensinar com materiais didáticos em língua estrangeira ou de forma bilíngue. A organização escolar atendia os interesses das comunidades étnicas. As associações culturais e escolares e as congregações religiosas foram muito importantes na construção e manutenção das escolas étnicas, pagamento dos professores, aquisição de material didático e organização pedagógica, reforçando a importância do associativismo. (RENK, 2012, p. 1048).
\end{abstract}

A "Associação Escolar Bratislava” tinha estatuto, livro-caixa e atas. Cada sócio pagava $3 \$ 000$ réis por mês de contribuição. Com o dinheiro arrecadado a Associação construiu e manteve a escola por alguns anos (AZEVEDO, 1996).

No início da colonização, a região denominada atualmente Cambé, pertencia à Comarca de Londrina, por isso, no período da construção da escola, o município de Londrina contribuiu financeiramente com a construção e a manutenção da escola. Entretanto, Capelo afirma que: "embora o município tenha con- tribuído com subvenções para as escolas estrangeiras e pagamentos de professores, não desenvolveu uma política educacional na região" (CAPELO, 200, p. 56).

Depois de instalada a escola, as comunidades étnicas escolhiam seus próprios professores, que geralmente era um adulto alfabetizado e com mais conhecimento no grupo. Dessa forma, o primeiro professor da Escola Bratislava foi Bruno Comége, pertencente ao mesmo grupo étnico e morador da Colônia Bratislava. O salário dele era pago pela contribuição dos pais dos alunos à Associação Escolar (AZEVEDO, 1996).

A escola foi construída em proporções modestas: tinha apenas uma sala de aula. A classe era composta por uma turma multisseriada, e o professor provavelmente morava nas dependências da própria escola. Esse padrão de escola configurava o modelo das escolas isoladas que foram instaladas, principalmente, nas regiões rurais do Norte do Paraná (CAPELO, 2000).

Após um ano de funcionamento da Escola Bratislava, em abril de 1937, foi nomeada uma professora municipal para a escola, com o salário mensal de 150 mil réis. Entretanto, os moradores da Colônia Bratislava não aceitaram a presença da professora e continuaram mantendo o professor Comége por cerca de mais três anos, pois os moradores da colônia temiam que a presença de uma professora brasileira pudesse atrapalhar o processo de transmissão cultural para as crianças da colônia (DESCORTEZ..., 1939).

A discussão sobre a formação do homem nacional já acontecia no Paraná nas primeiras décadas do século XX. Nesse aspecto, a nomeação de uma professora municipal para a Escola Bratislava fazia parte do projeto de nacionalização dos estrangeiros que moravam na região. Outro fator que contribuiu com a municipalização da Escola Bratislava foi o fato de a Associação Escolar não ter conseguido se manter, devido ao número insuficiente de sócios. Segundo o Estatuto da Associação, de acordo com o dispositivo no estatuto, a Associação teve que 
transferir seus bens à Prefeitura, inclusive a escola (TIRANDELLI, 1988).

O fechamento de escolas estrangeiras e a ampliação das políticas de nacionalização impuseram a necessária presença estatal na regulamentação do sistema educacional brasileiro. Com o processo de nacionalização, muitas associações foram extintas, já as escolas foram assumidas pelo poder público, algumas foram abandonadas e outras demolidas.

A Escola Bratislava, por ser de origem étnica, foi alvo de ações nacionalizantes impostas pela legislação que aconteceram progressivamente por meio da presença de professores brasileiros, da mudança curricular e da fiscalização, entre outras ações. No entanto, o "xeque-mate" do poder público aconteceu com a completa municipalização da escola, no ano de 1944.

A municipalização da escola aconteceu pautada no Decreto n. ${ }^{\circ} 19.513$, de 25 de agosto de 1945, no qual se estabelecia a concessão do auxílio federal para o ensino primário. De acordo com o Decreto, os recursos financeiros do Fundo Nacional de Ensino Primário seriam destinados anualmente aos estados, com o objetivo de promover a ampliação e a melhoria dos sistemas escolares de ensino primário em todo o país.

A Escola Bratislava, após ser municipalizada, funcionou até o ano 1948, quando teve seu nome alterado para Escola Municipal Manoel Ribas. A escolha do nome da instituição não ocorreu apenas em homenagem à memória de Manoel Ribas, interventor no Paraná na Era Vargas, mas como uma maneira do poder público afirmar o "abrasileiramento" da escola, eliminado toda a forma de lembrança ao país de origem dos imigrantes que habitavam a colônia, a começar pela substituição do nome.

A mudança do nome da escola estava em concordância com a Lei Orgânica do Ensino Primário (1946), a qual prescrevia que:
Aos estabelecimentos de ensino primário poderão ser atribuídos nomes de pessoas, já falecidas, que hajam prestado relevantes serviços à humanidade, ao país, Estado ou ao Município, e cuja vida pública e particular possa ser apontada às novas gerações. (BRASIL, 1946, p. 1).

Com o aumento da população na região rural de Cambé, principalmente na região Bratislava, houve a necessidade da ampliação da escola. Dessa forma, no ano de 1949, foi construído o Grupo Escolar Rural Manoel Ribas em substituição da antiga Escola Bratislava, que já não atendia aos anseios da comunidade.

O grupo escolar foi construído com três salas de aula, pois atendia do primeiro ao terceiro anos, já que o quarto ano deveria ser cursado no Grupo Escolar Olavo Bilac, na zona urbana de Cambé. Para que os alunos pudessem cursar o quarto ano, era necessário passar pelo exame de admissão. Cada sala possuía um quadro negro, uma mesa e uma cadeira para o professor, um armário e, em média, 17 carteiras duplas. 0 grupo contava, ainda, com a sala do diretor e um poço artesiano com 25 metros de profundidade, o qual era utilizado para desde a preparação dos alimentos até o uso diário dos 150 alunos que foram matriculados no primeiro ano de funcionamento da instituição (ESCOLA BRATISLAVA, 1967).

A história da Escola Bratislava não é um elemento isolado da realidade educacional do país, mas está inserida nesse contexto como um produto dessa época histórica. Os aspectos analisados, até agora, foram importantes para a compreensão dos fatores que contribuíram para a edificação e a instituição dessa unidade escolar no Paraná.

A municipalização da escola e a sua transformação em grupo escolar rural estiveram atreladas à decadência da Colônia Bratislava e a sua transformação em um bairro rural, haja vista que as políticas de nacionalização dos governos federal, estadual e municipal foram bem sucedidas (TIRANDELLI, 1988). 
A transformação da colônia em bairro esteve condicionada, também, à mudança das famílias para o centro urbano de Cambé ou para cidades vizinhas, como Londrina e Rolândia, para oportunizar às crianças um grau maior de estudo, bem como por fatores climáticos, por exemplo, as geadas que devastaram diversas plantações de café na região. Outro fator importante que contribuiu para a decadência da colônia é que muitos proprietários vendiam suas propriedades na região Bratislava, para comprar terras em regiões em processo de "colonização". Uma vez que, devido à região de Cambé já estar urbanizada, conseguiam um valor alto pelas propriedades. Pois,

Atraídos pela "marcha para o oeste", juntavam-se a muitos milhares de migrantes, que avançavam, devorando as últimas florestas virgens do Paraná. Esses fatores, em conjunto, precipitaram a mudança no perfil humano e cultural do patrimônio, (AZEVEDO, 1996, p. 39).

Apesar das mudanças ocorridas na região, é possível afirmar que a escola desenvolveu um papel de relevância social e cultural, principalmente para os moradores da região, que viam na educação a oportunidade de manter presentes os laços com o país de origem.

\section{CONCLUSÃO}

Com esta pesquisa, foi possível perceber que, apesar de a Escola Bratislava ser uma instituição importante para discutir o processo educacional rural na região norte do Paraná e também o início da educação escolar no município de Cambé, há a carência de documentos os quais permitam a constituição da historiografia da instituição. 0 pequeno número de documentos organizados pode ser devido ao fato de que as instituições de origem étnicas passaram por um processo de "desaparecimento" físico e histórico após as políticas nacionalistas de Vargas e, ainda, à falta de cultura de preservação de fontes. Sendo assim, a falta de documentos muitas vezes contribuiu para uma narrativa histórica linear e pautada na visão do pioneiro, que não raro é tido como um herói.
A história da Escola Bratislava não está desvinculada do contexto geral, pois junto ao processo de municipalização da instituição da escola forçado pelo processo político da época veio, também, a decadência da colônia, que com o passar dos anos transformou-se em um bairro rural. Mesmo assim, é possível afirmar que a história da Escola Bratislava é importante para a composição da história da fundação de Cambé, pois a região na qual a instituição foi instalada pode ser considerada uma das primeiras que foram loteadas pela empresa CTNP. Nesse aspecto, a escola, nos primeiros anos de sua existência, desempenhou um papel significativo para a manutenção da cultura étnica dos estrangeiros que compraram propriedades na localidade, bem como contribuiu para a formação de cidadãos cambeenses com o espírito patriótico.

Mediante o processo de decadência da colônia na qual a escola estava instituída, é possível afirmar que as políticas nacionalizantes da Era Vargas foram bem-sucedidas na região, pois abrasileiraram os moradores, usando como instrumento a educação escolar ofertada na instituição pesquisada.

A escola pode ser considerada, de fato, referência na região, no que concerne à educação, pois, após todo o processo de expansão urbana da região e o êxodo rural crescente, a instituição ainda se encontra ativa, funcionando como uma escola municipal rural na mesma região onde foi instalada na década de 1930.

\section{REFERÊNCIAS}

\section{AZEVEDO, José Júlio de. Bratislava, um ponto}

de encontro na história. Cambé, 1996. (Texto datilografado).

BRASIL. Decreto $n^{0}$ 19.513. Disposições

regulamentares destinadas a reger a concessão do auxílio federal para o ensino primário. 1945. Disponível em: <http://www2.camara.leg.br/ 
legin/fed/decret/1940-1949/decreto-19513-25agosto-1945-479511-publicacaooriginal-1-pe. html>. Acesso em: 8 abr. 2013.

BRASIL. Decreto n.0 8.529/46. Lei Orgânica do Ensino Primário. 1946. Disponível em: <http:// www.soleis.adv.br/leiorganicaensinoprimario.htm>. Acesso em: 12 jan. 2013.

CAMBÉ. Cambé: repensando a sua História. Cambé: Gráfica e Editora, 1992. p. 106.

CAPELO, Maria Regina Clivati. Educação, escola e diversidade cultural no meio rural de Londrina: quando o presente reconta o passado. 2000. 287f. Tese (Doutorado em Educação, Sociedade e Cultura) - Universidade Estadual de Campinas, Campinas, 2000.

CHIES, Cláudia; YOKOO, Sandra Carboner. Colonização do norte paranaense: avanço da cafeicultura e problemas decorrentes deste processo. Rev. GEOMAE, Campo Mourão, v.3, n.11ำ sem. 2012. p.27-44.

CORTEZ, Edna Scalon. Danziger hof: a hospedaria dos danziguenses em Cambé. Cambé: Objetiva, 2012.

DESCORTEZ e impatriótico, prohibe a professora de passar em seus terrenos para ir a escola. Jornal Paraná-Norte, Londrina, 13 ago. 1939. p.3.

EIDAM, Rodrigo; NASCIMENTO, Maria Isabel Moura.

A escola particular e a imigração alemã: o professor na comunidade rural do Paraná. 2011. Disponível em: <http://www.histedbr.fae.unicamp.br/acer_histedbr/ jornada/jornada7/_GT3\%20PDF/A\%20ESCOLA\%20 PARTICULAR\%20E\%20A\%20IMIGRA\%c7\%c30\%20 ALEM\%c3.pdf>. Acesso em: 10 dez. 2013.

ESCOLA BRATISLAVA. Relatório histórico da Escola Bratislava. Cambé, 1967. 53p.
FAUSTO, Boris. O Estado Novo no contexto internacional. In: PANDOLFI, Dulce (Org.).

Repensando o Estado Novo. Rio de Janeiro: FGV, 1999. p.17-20.

\section{HALL, Michael. Trabalhadores Imigrantes.}

Trabalhadores. Campinas: Secretaria Municipal de Cultura, Esportes e Turismo, n.3, 1989. p.3-15.

MELO, Cristiane Silva; MACHADO, Maria Cristina Gomes. A organização da instrução pública no estado do Paraná no início da república: o decreto n. ${ }^{\circ} 31$, de 29 de janeiro de 1890. Revista HISTEDBR On-line, Campinas, n.38, jun. 2010. p.248-260.

NEVES, Izaura Ferreira. Depoimento dado a Angela Maria Ribeiro e Elaine Garcia. Concedido ao Museu Histórico de Cambé em 25 de abril de 1985.

NOELLI, Francisco Silva; MOTA, Lucio Tadeu. A pré-História da região onde se encontra Maringá, Paraná. In: DIAS, Reginaldo B.; GONÇALVES, José H.R. (Org.). Maringá e o Norte do Paraná. Maringá: Eduem, 1999. p.5-19.

RENK, Valquíria. Professores de escolas étnicas no Paraná: manter a cultura ou cumprir as leis? Diálogo Educ, v.12, n.37, 2012. p.1045-1064.

STECA, Lucinéia Cunha; FLORES, Mariléia Dias.

História do Paraná: do século XVI à década de 1950. Londrina: UEL, 2002.

\section{TIRANDELLI, Rosa Maria Gallo. A Colônia}

Bratislava: a unidade familiar e o bairro rural em mudança. 1988. 153f. Dissertação (Mestrado em Sociologia Rural) - Universidade Federal do Rio Grande do Sul, Porto Alegre, 1988.

TOMAZI, Nelson Dacio. Norte do Paraná: História e fantasmagorias. 1997. 338f. Tese (Doutorado em História) - Universidade Federal do Paraná, Curitiba, 1997. 
1. Doutor em Educação pela Universidade Estadual de Campinas (Unicamp), professor do Departamento de Fundamentos da Educação e do Programa de Pós-Graduação em Educação da Universidade Estadual de Maringá (UEM), Maringá, PR - Brasil. E-mail: caatoledo@uem.br

2. Graduada em pedagogia pela Universidade Estadual de Londrina (UEL) e Mestre em Educação pela Universidade Estadual de Maringá (UEM), em 2014. Professora colaboradora no Departamento de Educação da Universidade Estadual de Londrina (UEL), Londrina. E-mail: isabelbarion@uel.br. Aceito em: 28 de agosto de 2015

Esta pesquisa foi realizada para a elaboração da dissertação de Mestrado intitulada: Educação em Cambé: História e memória da Escola Bratislava em Cambé (1934-1949) - UEM, 2014. 